\title{
$17 \beta$-estradiol regulates the malignancy of cancer stem-like cells derived from the MCF7 cell line partially through Sox2
}

\author{
LIAN GUO, FENG LI, MENGYUAN WANG, YUE XU, \\ BANGQIONG WANG, DONGCHUAN RAN and XIANXIANG ZHANG
}

Department of Endocrinology, Chongqing Three Gorges Central Hospital, Wanzhou, Chongqing 404000, P.R. China

Received October 14, 2016; Accepted April 4, 2017

DOI: $10.3892 / \mathrm{ol} .2018 .7796$

\begin{abstract}
As a major common malignant tumor in women, the malignant behavior of breast cancer, which includes tumorigenesis and metastasis, is associated with estrogen, particularly $17 \beta$-estradiol (E2). With accumulating evidence demonstrating that cancer stem-like cells (CSCs) serve a function in the malignant behavior of breast cancer, including metastasis, recurrence and chemoresistance, the effects of E2 on the physiological processes of CSCs have been attracting more attention. In the present study, in order to investigate the effects of E2 on CSCs, CSCs from the MCF7 breast cancer cell line were isolated and treated with 1, 10 and $50 \mathrm{nM} \mathrm{E2}$. Detection of cell proliferation following E2 treatment revealed that $10 \mathrm{nM}$ E2 treatment inhibited cell proliferation, whereas $50 \mathrm{nM}$ E2 treatment resulted in the induction of apoptosis on CSCs. In order to further investigate the effects of E2 treatment on migration, colony formation and the self-renewal capacity of CSCs in vitro, cells were treated with 1 and $10 \mathrm{nM}$ E2. As expected, compared with mock group, the self-renewal capacity of the CSCs was slightly increased by $10 \mathrm{nM}$ E2 treatment, while $1 \mathrm{nM}$ exhibited no observable effect. E2 treatment demonstrated different effects on the proliferation, migration, colony formation and self-renewal capacity of CSCs in a dosedependent manner.
\end{abstract}

\section{Introduction}

In women, breast cancer is a major cause of cancer-associated mortality globally. Each year, $\sim 1.4$ million women are diagnosed with breast cancer, and $>0.45$ million women succumb to the disease (1). According to data from the World Health Organization, since 2008, there has been an $20 \%$ increase in the number of diagnosed patients with breast cancer per year.

Correspondence to: Dr Xianxiang Zhang, Department of Endocrinology, Chongqing Three Gorges Central Hospital, 165 Xicheng Road, Wanzhou, Chongqing 404000, P.R. China E-mail: xianxiangzhang@163.com

Key words: 17 $\beta$-estradiol, cancer stem-like cell, breast cancer, self-renewal capacity, estrogen receptor $\alpha$
Of the multitude of factors associated with the tumorigenesis of breast cancer, age is the strongest risk factor. Unlike numerous cancers that demonstrate an increase in incidence rate during the fifth decade of life, the incidence rate for breast cancer increases in the third decade of life, which is believed to be due to the effects of ovarian hormones on breast tissue (2-4).

The association between certain hormone levels and the increased risk of breast cancer indicates the critical function of hormones in the processes of breast cancer. Estrogens, particularly $17 \beta$-estradiol (E2), have been demonstrated to drive the tumorigenic processes of breast cancer (5). It has been reported that $\mathrm{E} 2$ drives the tumorigenesis of breast cancer by binding to estrogen receptor $\alpha(E R \alpha)$ and regulating the expression of the downstream genes (6-9). Yager and Davidson (10) described several potential pathways that may explain how E2 treatment promotes breast cancer proliferation, migration and invasion. However, it has also been reported that E2 serves a contradictory effect on breast cancer cells in a concentration-dependent manner. Zhao et al (11) demonstrated that a high concentration of E2 induces apoptosis independent of the presence of ER $\alpha$, whereas a low concentration of E2 promotes the proliferation of breast cancer cells through ER $\alpha$. A high dose of E2 treatment caused a change in the levels of metastasis-associated lung adenocarcinoma transcript-1 (non-protein-coding) in MCF7 cells, which consequently caused the inhibition of the proliferation of breast cancer cells, as well as inhibiting the migratory, invasive and colony-formation abilities. Further studies are required to confirm these potential mechanisms.

Stem cells or cells that possess stem-like cell properties are considered to be fundamental in breast cancer initiation and progression (12). The small subpopulation of stem cells that exist within solid tumors, cancer stem-like cells (CSCs), are heterogeneous and have been demonstrated to be responsible for the regeneration of breast tumors (13). In this previous study, the different mechanisms of CSCs were assessed, including cellular markers cluster of differentiation $44^{+} / 24^{-/ l o w}$, aldehyde dehydrogenase 1 expression, and mammosphere formation and self-renewal capacity. The differential gene expression patterns of breast cancer cells and the CSCs derived from breast cancer raise the following question: How does E2 treatment of these two types of cell affect their physiological processes?

In order to answer this question, in the present study, the effects of different concentrations of E2 treatment on breast 
cancer cells and CSCs were examined. To elucidate the potential molecular mechanisms underlying the effect of E2 on CSCs, the levels of the transcription factors associated with self-renewal capacity were determined. The results of the present study demonstrated the effects of E2 on CSCs derived from breast cancer, and the partial underlying molecular mechanism.

\section{Materials and methods}

Cell culture. The human breast adenocarcinoma cell line MCF7 was obtained from the American Type Culture Collection (Manassas, VA, USA) and frozen in liquid nitrogen $\left(-196^{\circ} \mathrm{C}\right)$ in the laboratory. Cells were kept in $100 \mathrm{~cm}^{2}$ dishes that contained $10 \mathrm{ml}$ RPMI-1640 medium (Thermo Fisher Scientific, Inc., Waltham, MA, USA) supplemented with $10 \%$ fetal bovine serum (Thermo Fisher Scientific, Inc.) and 1\% penicillin/streptomycin (Thermo Fisher Scientific, Inc.) in a humidified atmosphere containing $5 \% \mathrm{CO}_{2}$ at $37^{\circ} \mathrm{C}$. The medium was replaced every 3 days.

Culture of CSCs from MCF7 cells. The suspended MCF7 cells were diluted to a density of $10^{6}$ cells $/ \mathrm{ml}$ in sphereforming medium (SFM; Gibco; Thermo Fisher Scientific, Inc.) which was supplemented with $10 \mathrm{ng} / \mathrm{ml}$ basic fibroblast growth factor (bFGF; PeproTech, Inc., Rocky Hill, NJ, USA), $20 \mathrm{ng} / \mathrm{ml}$ epidermal growth factor (EGF; PeproTech, Inc.) and 2\% B27 (Thermo Fisher Scientific, Inc.). The medium was half-replaced every 3 days and the cells were passaged every 10-15 days.

Reverse transcription-quantitative polymerase chain reaction $(R T-q P C R)$. In order to detect the expression levels of ER $\alpha$, octamer-binding transcription factor 4 (Oct4), sex-determining region Y-box 2 (Sox2), Krüppel-like factor 4 (Klf4) and MYC proto-oncogene (c-Myc), total RNA was isolated using TRIzol reagent (Thermo Fisher Scientific, Inc.) following the manufacturer's protocol. Total RNA $(0.5 \mu \mathrm{g})$ was added to the RT reaction mixture in a final volume of $25 \mu \mathrm{l}$ using the RevertAid RT Reverse Transcription kit (Thermo Fisher Scientific, Inc.) according to the manufacturer's protocol. cDNA was used for qPCR using SYBRGreen SuperMix (Thermo Fisher Scientific, Inc.) on a ABI7500 device (Applied Biosystems; Thermo Fisher Scientific, Inc.). For each cycle: $10 \mathrm{sec}$ at $95^{\circ} \mathrm{C}$ for denaturation, $45 \mathrm{sec}$ at $60^{\circ} \mathrm{C}$ for annealing and extension, repeat 35 cycles. The primer pairs used for amplification were as follows: ER $\alpha$ forward, 5'-CCCACTCAACAGCGTGTCTC-3' and reverse, 5'-CGTCGATTATCTGAATTTGGCCT-3'; Oct4 forward, 5'-CTGGGTTGATCCTCGGACCT-3' and reverse, 5'-CCATCGGAGTTGCTCTCCA-3'; Sox2 forward, 5'-GCC GAGTGGAAACTTTTGTCG-3' and reverse, 5'-GGCAGC GTGTACTTATCCTTCT-3'; Klf4 forward, 5'-CCCACATGA AGCGACTTCCC-3' and reverse, 5'-CAGGTCCAGGAGATC GTTGAA-3'; c-Myc forward, 5'-GGCTCCTGGCAAAAG GTCA-3' and reverse, 5'-CTGCGTAGTTGTGCTGATGT-3'. For data analysis, the DDCq method was used (14). All experiments were performed three times.

Cell counting Kit-8 (CCK-8) assay. The proliferation of CSCs was measured using CCK-8 (Sigma-Aldrich; Merck
KGaA, Darmstadt, Germany) according to the manufacturer's protocol. CSC spheres were signalized using TrypLE ${ }^{\text {тм }}$ Express (Life Technologies, Grand Island, NY, USA) and a total amount of $5 \times 10^{3} \mathrm{CSC}$ were seeded and incubated in 96-well plates for $24 \mathrm{~h}$. Subsequently, the 0, 1, 10 or $50 \mathrm{nM}$ of E2 (Sigma-Aldrich; Merck KGaA) was added and co-incubated with the CSCs for $1-5$ days at $37^{\circ} \mathrm{C}$ in $5 \%$ $\mathrm{CO}_{2}$ incubator. Each day, $10 \mu \mathrm{l}$ CCK- 8 reagent was added to each well and incubated for $4 \mathrm{~h}$ at $37^{\circ} \mathrm{C}$. Absorbance was then measured at $450 \mathrm{~nm}$. All experiments were performed in triplicate and repeated at least twice.

Caspase-3/7 activity assay. Target cells were seeded in 96-well plates at a concentration of $5 \times 10^{3}$ cells $/ \mathrm{ml}$. Following exposure to $0,1,10$ or $50 \mathrm{nM}$ E2 for $24 \mathrm{~h}$ at $37^{\circ} \mathrm{C}$, caspase3/7 activity was analyzed using Caspase-Glu ${ }^{\mathrm{TM}} 3 / 7$ assay kit (Promega Corporation, Madison, WI, USA) by following the manufacturer's protocol. Briefly, Caspase-Glu ${ }^{\mathrm{TM}}$ reagents were added and incubated with cells for $1 \mathrm{~h}$ at $37^{\circ} \mathrm{C}$ and the absorbance at a wavelength at 520-530 nm was determined using a microplate reader (Synergy 2 Multi-Mode Microplate Reader; BioTek Instruments, Inc., Winooski, VT, USA).

Immunofluorescence analysis. Cells were fixed in 4\% paraformaldehyde for $15 \mathrm{~min}$ at room temperature, and incubated with PBS supplemented with $0.1 \%$ Triton X-100 for $10 \mathrm{~min}$. Permeabilized cells were blocked with $5 \%$ bovine serum albumin (BSA; Sigma-Aldrich; Merck KGaA) and incubated with antibody against ER $\alpha$ (cat. no. ab32063; Abcam, Cambridge, UK) at a dilution of 1:2,000 overnight at $4^{\circ} \mathrm{C}$. Cells were washed and further stained with Alex Fluor ${ }^{\circledR}$ 594-conjugated goat anti-mouse secondary antibodies (cat. no. R37121; Life Technologies, Grand Island, NY, USA) at a dilution of 1:1,000 for $2 \mathrm{~h}$ in darkness. Following washing with PBS, cells were imaged under a X71 (U-RFL-T) fluorescence microscope (Olympus Corporation, Tokyo, Japan) at a magnification of $\mathrm{x} 400$.

Western blot. Cells were pelleted and washed three times with PBS and resuspended with lysis buffer (50 mM Tris, $150 \mathrm{mM} \mathrm{NaCl}, 1 \%$ Nonidet P40 (NP-40), and $0.25 \%$ sodium deoxycholate). Lysate was centrifuged for $5 \mathrm{~min}$ at $12,000 \mathrm{x} \mathrm{g}$, $4^{\circ} \mathrm{C}$ to remove cell debris. The supernatant was removed into a fresh tube before sample buffer was added (Guangzhou RiboBio Co., Ltd., Guangzhou, China). Following incubation at $100^{\circ} \mathrm{C}$ for $10 \mathrm{~min}$, samples were separated SDS-PAGE and transferred to polyvinylidene difluoride membranes (Bio-Rad, Hercules, CA, USA), which were pre-treated with PBS containing 5\% BSA and $0.3 \%$ Tween 20. Membranes were probed with antibodies against human ER $\alpha$ (Cat. No.: ab32063), activated caspase-3 (Cat. No.: ab2302), $\beta$-actin (Cat. No.: ab8226), GAPDH (Cat. No.: ab8245) which were bought from Abcam (Cambridge, UK) at dilution of 1:1,000. The signals were visualized using a enhanced chemiluminescence substrate (Supersignal West Femto Luminal/Enhancer Solution; Thermo Fisher Scientific, Inc.) and blotted on X-ray films in a dark room. To quantify the western blots, ImageJ software (Version. 1.48a; National Institutes of Health, Bethesda, MD, USA) was used to quantitatively measure the bands and normalized using $\beta$-actin. 
A 7 14 21
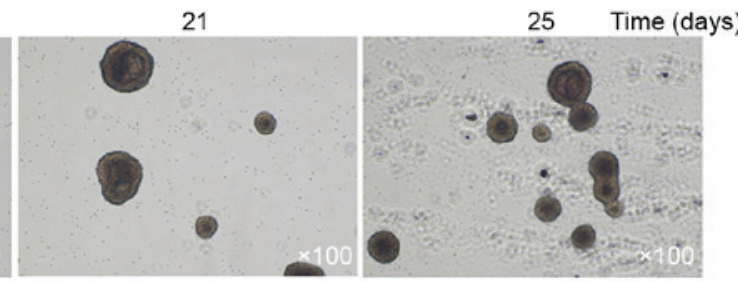

B

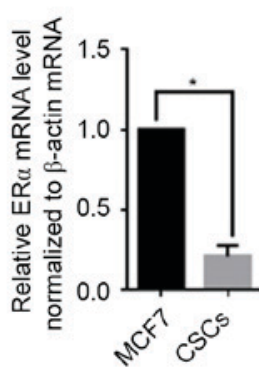

C

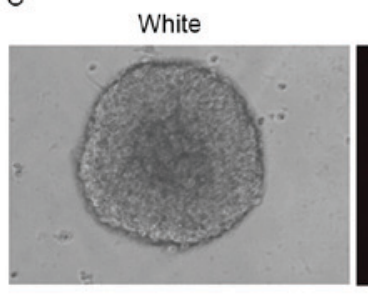

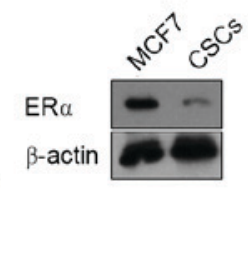

Anti-ER $\alpha$ antibody

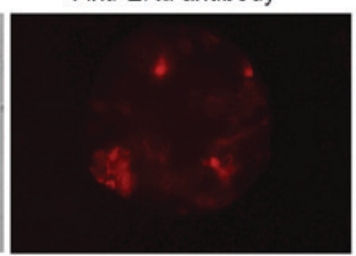

Figure 1. Isolation of CSCs from MCF7 cells and the detection of ER $\alpha$ expression on the sphere. (A) Following culture in sphere-forming medium, images of sphere formation were captured at days 7, 14,21 and 25. (B) The reverse transcription-quantitative polymerase chain reaction was performed to detect the mRNA level of ER $\alpha$ (left panel) and a semi-quantitative western blot was performed to detect the protein level of ER $\alpha$ (right panel). (C) Immunofluorescence staining of ER $\alpha$ was used to identify the ER $\alpha$-positive subpopulation in CSCs. ${ }^{*} \mathrm{P}<0.05$, with comparisons indicated by lines. CSCs, cancer stem-like cells; $\mathrm{ER} \alpha$, estrogen receptor $\alpha$.

Transwell migration assay. The migration of CSCs was quantified using a Transwell assay (EMD Millipore, Billerica, MA, USA). Cells ( $\left.1 \times 10^{4}\right)$ were suspended with RPMI-1640 medium containing 0,1 or $10 \mathrm{nM}$ E2 and seeded onto the surface of the upper chamber. RPMI-1640 medium supplemented with $10 \%$ fetal bovine serum (Life Technologies, Grand Island, NY, USA) was added to the lower well. The plates were incubated for $24 \mathrm{~h}$ at $37^{\circ} \mathrm{C}$ and, subsequently, migrated cells were stained with $0.5 \%$ crystal violet at room temperature for $30 \mathrm{~min}$ followed by three washes with PBS and imaged under a X71 (U-RFL-T) fluorescence microscope (Olympus Corporation) at a magnification of $\times 200$.

Self-renewal capacity assay. A total of $2 \times 10^{3}$ signalized CSCs were plated into 24-well plates. The cells were cultured in the SFM in the presence of 0,1 or $10 \mathrm{nM}$ E2 for 7-15 days. The spheres $>40 \mu \mathrm{m}$ in diameter were counted under an X71 (U-RFL-T) fluorescence microscope (Olympus Corporation) at a magnification of $\mathrm{x} 40$.

Statistical analysis. Data are presented as the mean \pm standard error of the mean. The data were evaluated statistically using one-way analysis of variance followed by the Tukey test for paired observations. The two-tailed Student's t-test was used to compare two groups. $\mathrm{P}<0.05$ was considered to indicate a statistically significant difference. All experiments were performed at least three times independently.

\section{Results}

CSCs derived from MCF7 express a lower ER $\alpha$ level compared with MCF7 cells. To isolate the CSC subpopulation from MCF7 cells, $1 \times 10^{6}$ MCF7 cells were incubated in Dulbecco's modified Eagle's medium/Ham's F12 supplemented with B27, bFGF and EGF for 25 days. Images were taken at days 7, 14, 21 and 25. As presented in Fig. 1A, the CSC spheres rapidly
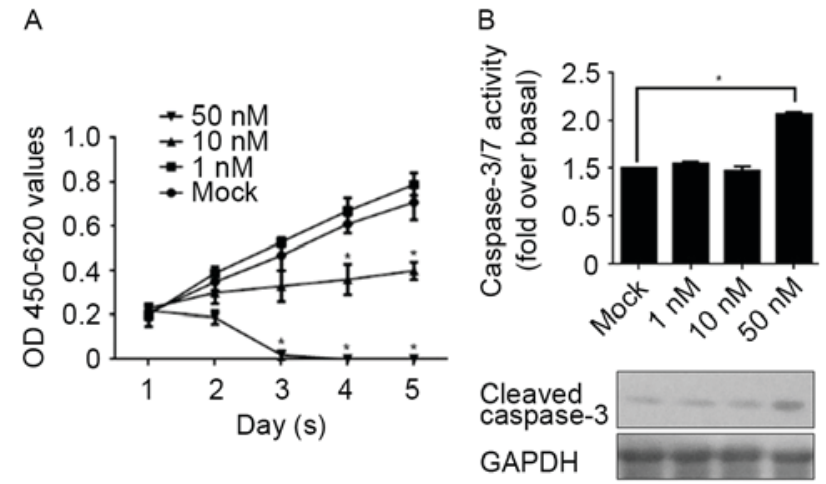

Figure 2. Identifying the effects of E2 treatment on cell proliferation and apoptosis. (A) A Cell Counting Kit-8 assay was performed to demonstrate the effect of 1, 10 and $50 \mathrm{nM}$ E2 treatment on the proliferation of CSCs. (B) Caspase-3/7 activity was assayed (upper panel) and the cleaved form of caspase- 3 was detected using a western blot. " $\mathrm{P}<0.05$, with comparisons indicated by lines. E2, 17 $\beta$-estradiol.

increased in size. Owing to the presence of ER $\alpha$ on the surface of MCF7 cells, the potential for CSCs derived from MCF7 to express ER $\alpha$ was examined. According to the RT-qPCR and semi-quantitative western blot assays, the total amount of mRNA and protein from ER $\alpha$ in CSCs decreased markedly when compared with that in MCF7 cells (Fig. 1B). In order to determine whether the decrease in ER $\alpha$ mRNA and protein levels occurred in each CSC, immunofluorescent staining was utilized to demonstrate the ER $\alpha$-positive cells in spheres. As presented in Fig. 1C, a small section of ER $\alpha$-positive CSCs in the sphere was detectable, whereas further cells exhibited an $\mathrm{ER} \alpha$-negative status.

E2 treatment regulates the proliferation and apoptosis of CSCs in a dose-dependent manner. It has been reported that the effect of E2 treatment varies depending on the concentration. Low 

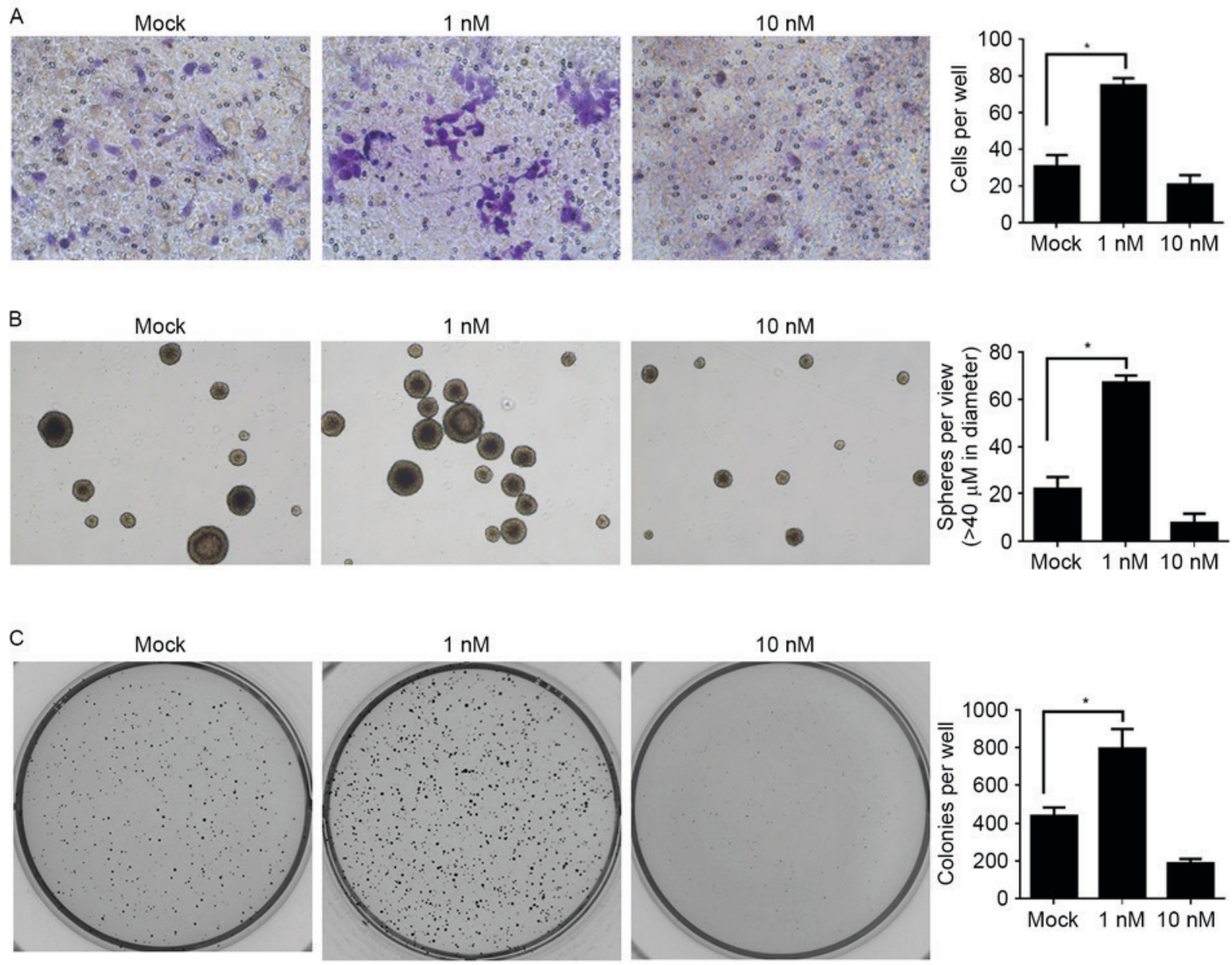

Figure 3. The effects of E2 treatment on CSC migration, self-renewal capacity and colony formation. (A) A Transwell assay without Matrigel was used for migration analysis. (B) Sphere formation was performed in sphere-forming medium for $14-20$ days. (C) Colony formation in soft agar was performed. ${ }^{*} \mathrm{P}<0.05$, with comparisons indicated by lines. E2, 17ß-estradiol; CSCs, cancer stem-like cells.

doses or high doses of E2 treatment have opposing effects on cell proliferation. This indicates that, considering the decrease in ER $\alpha$ in CSCs, E2 treatment results in differential effects on CSCs according to the concentration. CSCs were treated with 1, 10 and $50 \mathrm{nM}$ E2 for 1-5 days and assessed using a CCK-8 assay for cell proliferation. In Fig. 2A, 1 nM E2 treatment was demonstrated to present no detectable effect on cell proliferation, whereas $10 \mathrm{nM}$ E2 treatment markedly decreased cell proliferation. Notably, $50 \mathrm{nM}$ E2 treatment directly eliminated all cells, meaning that this concentration of E2 treatment is fatal to CSCs. In order to identify whether the elimination of CSCs following $50 \mathrm{nM}$ E2 treatment was due to the induction of apoptosis, the activity of caspase-3/7 and the cleaved form of caspase-3 were detected separately. As expected, the results demonstrated that $50 \mathrm{nM}$ E2 treatment increased the activity of caspase-3/7, accompanied by the increase in the levels of the cleaved form of caspase-3 (Fig. 2B).

E2 treatment affects migration, self-renewal capacity and colony formation, potentially due to the regulation of Sox 2 . In order to further investigate the effects of E2 treatment on the physiological processes of CSCs, the effects on migration, self-renewal capacity and colony formation were assessed. Taking into consideration the fatal effect of the $50 \mathrm{nM} \mathrm{E} 2$ treatment, Mock, 1 and $10 \mathrm{nM}$ E2 treatments were employed
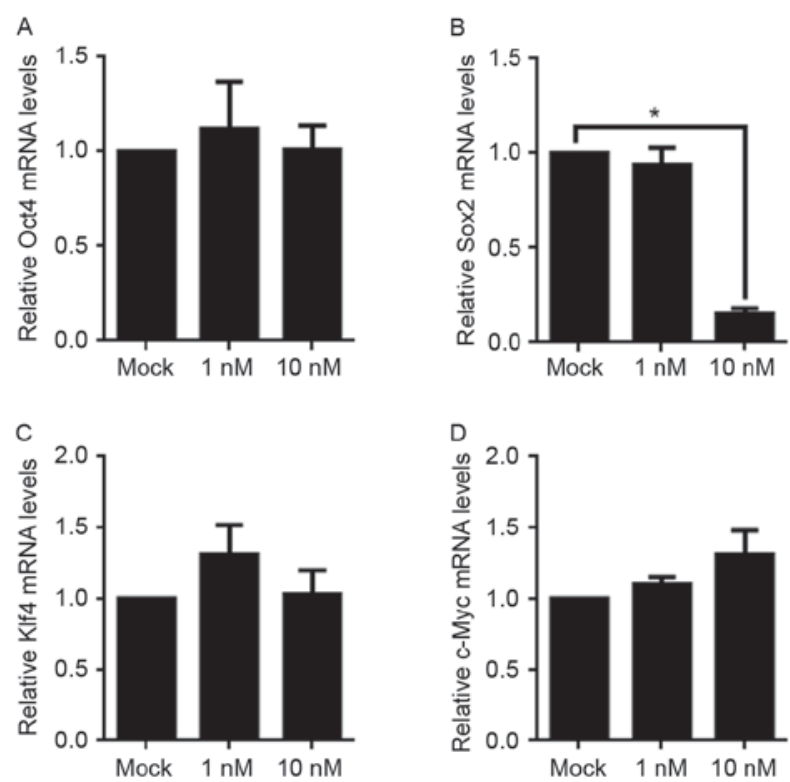

Figure 4. Reverse transcription-quantitative polymerase chain reaction analysis for the stem-maintaining factors following E2 treatment. Following the response to E2 treatment, the mRNA levels of Oct4 (A), Sox2 (B), K1f4 (C) and c-Myc (D) were detected. ${ }^{*} \mathrm{P}<0.05$ vs. the Mock group, as indicated by lines. E2, 17 $\beta$-estradiol; Oct4, octamer-binding transcription factor 4; Sox2, sex-determining region Y-box 2; Klf4, Krüppel-like factor 4; c-Myc, MYC proto-oncogene. 
for the following assays: For the migration assay, a Transwell assay without Matrigel coating was used. Compared with the Mock group, the $1 \mathrm{nM} \mathrm{E2-treated} \mathrm{group} \mathrm{promoted} \mathrm{the} \mathrm{migra-}$ tion of CSCs and, in contrast, the $10 \mathrm{nM}$ E2 treatment inhibited the migration of CSCs, but the difference was not significant (Fig. 3A). The assays for self-renewal capacity and colony formation revealed similar tendencies: When compared with the Mock group, the lower dose of E2 treatment $(1 \mathrm{nM})$ significantly promoted these processes and the higher dose of E2 treatment $(10 \mathrm{nM})$ inhibited these processes (Fig. 3B and C).

Owing to the fact that Oct4, Sox2, Klf4 and c-Myc serve critical functions in maintaining cell stemness, the aforementioned result which revealed the decreased stemness following $10 \mathrm{nM}$ E2 treatment prompted an interest in detecting the changes of the mRNA levels of these four factors. Using RT-qPCR, although Oct4, Klf4, and c-Myc levels were not altered, the mRNA level of Sox 2 was significantly decreased. This indicated that a decrease in Sox 2 mRNA expression may be the potential underlying molecular mechanism for the loss of stemness following E2 treatment (Fig. 4).

\section{Discussion}

E2 is believed to regulate the physiological processes of normal breast cells or breast cancer cells, depending on the presence of ER $(15,16)$. This is supported by the fact that ER $\alpha$ is frequently highly expressed in ER-positive breast cancer cells, and thus regulates the cell cycle in these cells, indicating that E2-ER $\alpha$ signaling serves a critical function in cell proliferation $(17,18)$. Notably, Zhao et al (11) reported that E2 also performs a regulatory function on breast cancer cells independent of ER $\alpha$. Consistently, in their results, a low level of E2 $(1 \mathrm{nM})$ was demonstrated to affect the proliferation of ER-positive MCF7 breast cancer cells, but not that of ER-negative MB231 breast cancer cells. However, a high dose of E2 (50-100 nM) markedly blocked proliferation and induced apoptosis in these two types of breast cancer cell.

In the present study, the difference in ER $\alpha$ expression between the CSCs derived from MCF7 cells and original MCF7 cells, and the effects of E2 treatment at a range of concentrations, were investigated. Initially, CSCs were obtained using a serum-free maintenance system and a confirmatory assay for their self-renewal capacity was performed (Fig. 1A). RT-qPCR and semi-quantitative western blot assays demonstrated that the mRNA and protein levels of ER $\alpha$ in MCF7 cells were significantly increased compared with that in CSCs derived from MCF7 cells (Fig. 1B). Notably, the fluorescent staining of ER $\alpha$ in the CSC sphere demonstrated that a small proportion of the CSCs presented an ER $\alpha$-positive signal, indicating the existence of two subpopulations of CSCs: An ER $\alpha$-positive subpopulation and an ERa-negative subpopulation (Fig. 1C). These two subpopulations of CSCs may be derived from two separate subpopulations of MCF7, or may be derived from the same population and subsequently differentiated into two subpopulations.

In the present study, the effects of different concentrations of $\mathrm{E} 2$ on a mixture of ER $\alpha$-positive and $\mathrm{ER} \alpha$-negative CSCs were tested due to the failure to separate these two subpopulations (data not shown). Owing to the unknown ratio of ER $\alpha$-positive and $\mathrm{ER} \alpha$-negative CSCs, no detectable promotion of proliferation was observed following $1 \mathrm{nME} 2$ treatment and, as expected, $10 \mathrm{nM}$ E2 treatment resulted in inhibition of proliferation, and
$50 \mathrm{nM}$ E2 treatment directly eliminated cell viability in $48 \mathrm{~h}$ by inducing apoptosis (Fig. 2A and B). Despite the lack of clarity regarding whether low doses of $\mathrm{E} 2$ treatment promote the proliferation of CSC in these two subpopulations, it was confirmed that a high dose of E2 treatment is fatal for them, independent of the existence of ER $\alpha$.

Because of the fatal effects of $50 \mathrm{nM} \mathrm{E} 2$ treatment, $10 \mathrm{nM}$ E2 treatment was employed for further investigation of migration, self-renewal capacity and colony formation. It was observed that $10 \mathrm{nM}$ E2 treatment universally inhibited these processes, whereas $1 \mathrm{nM} \mathrm{E} 2$ treatment had an opposing effect on them (Fig. 3).

The decreased maintenance of stemness of CSCs prompted an interest in detecting the expressional changes of Oct4, Sox 2, Klf4 and c-Myc, which are critical for stemness maintenance (19), and it was revealed that the Sox 2 mRNA level was significantly decreased by $50 \mathrm{nM}$ E2 treatment (Fig. 4).

In summary, the results of the present study confirmed the regulatory effects of different concentration of E2 treatment on CSCs derived from MCF7. It was identified that there were two subpopulation of CSCs derived from MCF7 and this may have resulted in the differential effects following E2 treatment. In addition, a high dose of E2 treatment may inhibit the malignancy of CSCs by decreasing their stemness through the downregulation of the Sox 2 expression level.

\section{Acknowledgements}

The authors would like to thank Miss Changjin Chen for the English editing.

\section{References}

1. Siegel R, Naishadham D and Jemal A: Cancer statistics, 2013. CA Cancer J Clin 63: 11-30, 2013.

2. Landis MD, Lehmann BD, Pietenpol JA and Chang JC: Patientderived breast tumor xenografts facilitating personalized cancer therapy. Breast Cancer Res 15: 201, 2013.

3. Hulka BS and Moorman PG: Breast cancer: Hormones and other risk factors. Maturitas 38: 103-116, 2001.

4. Moore NM and Nagahara LA: Physical biology in cancer. 1. Cellular physics of cancer metastasis. Am J Physiol Cell Physiol 306: C78-C79, 2014.

5. Osborne CK and Schiff R: Estrogen-receptor biology: Continuing progress and therapeutic implications. J Clin Oncol 23: 1616$1622,2005$.

6. Doisneau-Sixou SF, Sergio CM, Carroll JS, Hui R, Musgrove EA and Sutherland RL: Estrogen and antiestrogen regulation of cell cycle progression in breast cancer cells. Endocr Relat Cancer 10: 179-186, 2003.

7. Cunliffe HE, Ringnér M, Bilke S, Walker RL, Cheung JM, Chen Y and Meltzer PS: The gene expression response of breast cancer to growth regulators: Patterns and correlation with tumor expression profiles. Cancer Res 63: 7158-7166, 2003.

8. Basu A and Rowan BG: Genes related to estrogen action in reproduction and breast cancer. Front Biosci 10: 2346-2372, 2005.

9. Deroo BJ and Korach KS: Estrogen receptors and human disease. J Clin Invest 116: 561-570, 2006.

10. Yager JD and Davidson NE: Estrogen carcinogenesis in breast cancer. N Engl J Med 354: 270-282, 2006.

11. Zhao Z, Chen C, Liu Y and Wu C: $17 \beta$-Estradiol treatment inhibits breast cell proliferation, migration and invasion by decreasing MALAT-1 RNA level. Biochem Biophys Res Commun 445: 388-393, 2014.

12. Lamb R, Lehn S, Rogerson L, Clarke RB and Landberg G: Cell cycle regulators cyclin D1 and CDK4/6 have estrogen receptordependent divergent functions in breast cancer migration and stem cell-like activity. Cell Cycle 12: 2384-2394, 2013. 
13. Al-Hajj M, Wicha MS, Benito-Hernandez A, Morrison SJ and Clarke MF: Prospective identification of tumorigenic breast cancer cells. Proc Natl Acad Sci USA 100: 3983-3988, 2003.

14. Livak KJ and Schmittgen TD: Analysis of relative gene expression data using real-time quantitative PCR and the 2(-Delta Delta $\mathrm{C}(\mathrm{T})$ ) method. Methods 25: 402-408, 2001.

15. Miyoshi $Y$, Murase K, Saito $M$, Imamura $M$ and $O h K_{\text {: }}$ Mechanisms of estrogen receptor- $\alpha$ upregulation in breast cancers. Med Mol Morphol 43: 193-196, 2010.

16. Tyson JJ, Baumann WT, Chen C, Verdugo A, Tavassoly I, Wang Y, Weiner LM and Clarke R: Dynamic modelling of oestrogen signalling and cell fate in breast cancer cells. Nat Rev Cancer 11: 523-532, 2011.
17. Berger CE, Qian Y, Liu G, Chen $\mathrm{H}$ and Chen X: p53, a target of estrogen receptor (ER) $\alpha$, modulates DNA damage-induced growth suppression in ER-positive breast cancer cells. J Biol Chem 287: 30117-30127, 2012.

18. Platet N, Cathiard AM, Gleizes M and Garcia M: Estrogens and their receptors in breast cancer progression: A dual role in cancer proliferation and invasion. Crit Rev Oncol Hematol 51: 55-67, 2004.

19. Takahashi K and Yamanaka S: Induction of pluripotent stem cells from mouse embryonic and adult fibroblast cultures by defined factors. Cell 126: 663-676, 2006. 